\title{
EVALUATING THE POTENTIAL OF CONSUMER-GRADE SMART CAMERAS FOR LOW-COST STEREO-PHOTOGRAMMETRIC CROP-SURFACE MONITORING
}

\author{
S. Brocks ${ }^{a}$ *, G. Bareth ${ }^{\mathrm{a}}$ \\ ${ }^{a}$ Institute of Geography (GIS \& Remote Sensing Group), University of Cologne, Albertus-Magnus-Platz, 50923 Cologne, Germany \\ - (sebastian.brocks, g,bareth)@uni-koeln.de
}

\section{Commission VII, WG VII/5}

KEY WORDS: Crop, Surface, Monitoring, Stereoscopic, Multitemporal, Agriculture, Change Detection

\begin{abstract}
:
Crop-Surface-Models (CSMs) are a useful tool for monitoring in-field crop growth variability, thus enabling precision agriculture which is necessary for achieving higher agricultural yields. This contribution provides a first assessment on the suitability of using consumer-grade smart cameras as sensors for the stereoscopic creation of crop-surface models using oblique imagery acquired from ground-based positions. An application that automates image acquisition and transmission was developed. Automated image acquisition took place throughout the growing period of barley in 2013. For three dates where both automated image acquisition and manual measurements of plant height were available, CSMs were generated using a combination of AgiSoft PhotoScan and Esri ArcGIS. The coefficient of determination $\mathrm{R}^{2}$ between the average of the manually measured plant heights per plots and the average height of the developed crop surface models was $0.61(\mathrm{n}=24)$. The overall correlation between the manually measured heights and the CSM-derived heights is 0.78 . The average per plot of the manually measured plant heights in the timeframe covered by the generated CSMs range from 19 to $95 \mathrm{~cm}$, while the average plant height per plot of the generated CSMs range from 2.1 to $69 \mathrm{~cm}$. These first results show that the presented approach is feasible.
\end{abstract}

\section{INTRODUCTION}

Crop-Surface Models (CSMs) (Hoffmeister et al., 2010) are a useful tool for monitoring in-field crop growth variability, thus enabling precision agriculture: It can reap great benefits from remote sensing (Mulla, 2013). Precision agriculture is a necessity for achieving higher agricultural yields. These higher yields are needed globally to feed the growing world population. The suitability of using consumer grade cameras for close range surface measurements has been explored and verified in the past (Chandler et al., 2005, Habib et al., 2008), and while Digital Surface Models (DSMs) have been created for geomorphological, geophysical or vulcanological studies (James and Robson, 2012, Heng and Chandler, 2010, Chandler et al., 2002, James and Varley, 2012), there has been no recent research for monitoring crops using oblique stereo imagery. While CSMs are commonly created using stereo photographs acquired from nadir imagery taken from airborne carrier systems (Bendig et al., 2013) or by using Terrestrial Laser Scanning (TLS) systems (Hoffmeister et al., 2010, Tilly et al., 2014), this contribution provides a first assessment on the suitability of using consumer-grade smart cameras as sensors for the stereoscopic creation of crop-surface models using oblique imagery acquired from ground-based positions. Programmable smart cameras allow for the possibility of automated multitemporal image acquisition, thus further lowering costs when compared to conventional multi-temporal monitoring where images have to be acquired manually.

\section{METHODS}

\subsection{Study Site}

The data acquisition for this study was conducted on a field experiment located at the Campus Klein-Altendorf
(N 50 37'27’, E 6 $59^{\prime} 16^{\prime \prime}$ ), which is a part of the Faculty of Agriculture of the University of Bonn in western Germany. The study area was a collection of eight $3 \mathrm{~m}$ by $7 \mathrm{~m}$ plots (plots $1-4$ and 14-17) in a $12 \mathrm{~m}$ by $16.5 \mathrm{~m}$ area of a larger summer barley field in which 18 varieties of barley were cultivated with two different nitrogen treatments. The study area is shown in Figure 1.

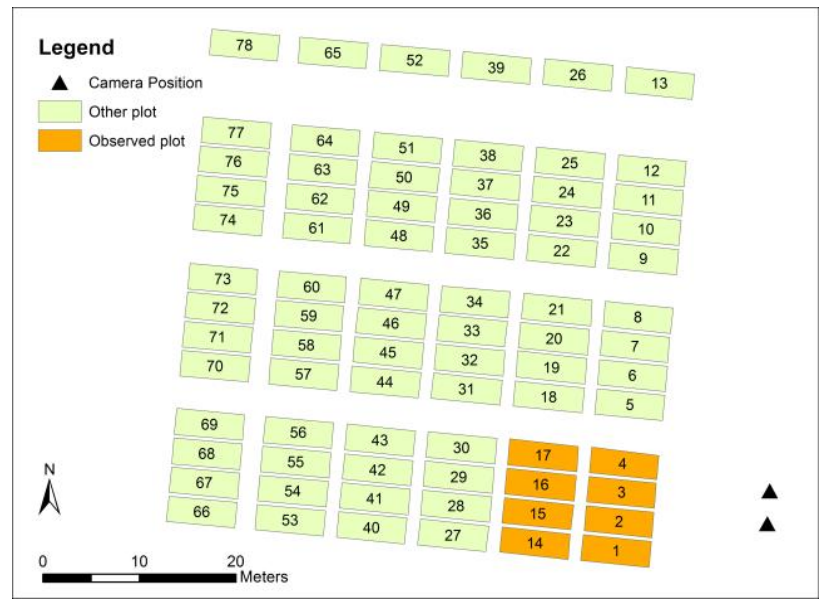

Figure 1. Plot Layout of the study area and Camera positions

The eight observed plots correspond to eight different varieties that where cultivated with a reduced nitrogen fertilization rate of $40 \mathrm{~kg} / \mathrm{ha}$. Differences in crop-height between the eight plots were expected because different barley varieties were being used. The field experiment was set up by the interdisciplinary research network CROP.SENSe.net (http://www.cropsense.unibonn.de), which is working towards non-destructively analysing

\footnotetext{
* Corresponding author.
} 
and screening plant phenotype and crop status such as nutrients and stress.

\subsection{Data acquisition}

2.2.1 Image data: For data acquisition, the consumer grade smart-camera Samsung Galaxy Camera EK-GC100 (Samsung 2014) was used. It features a $1 / 2.3$ " BSI CMOS image sensor with 16.3 million pixels and a $21 \mathrm{x}$ zoom lens with a focal length of $4.1 \sim 86.1 \mathrm{~mm}$ ( $35 \mathrm{~mm}$ film equivalent: $23 \sim 484 \mathrm{~mm}$ ) and has WIFI and 3G mobile network connectivity. Due to it running the Android operating system, it was possible to develop a custom application to automate the image acquisition. The application automatically acquires images at three different exposure times $(1 / 25 \mathrm{~s}, 1 / 50 \mathrm{~s}, 1 / 100 \mathrm{~s})$ and uploads the images after the acquisition to an FTP server reachable at a configurable IP address using the $3 \mathrm{G}$ wireless network connection available in the cameras. Figure 2 shows a screenshot of the Android application's user interface. As shown there, the interval between image acquisitions, the image resolution, the zoom and the starting time can be set, along with a filename prefix to uniquely identify the camera the images were captured with. The application starts a background service that wakes the camera only to acquire and upload the images; at all other times the camera is in standby mode in order to maximize battery life. For this reason, the application also does not acquire images at night.

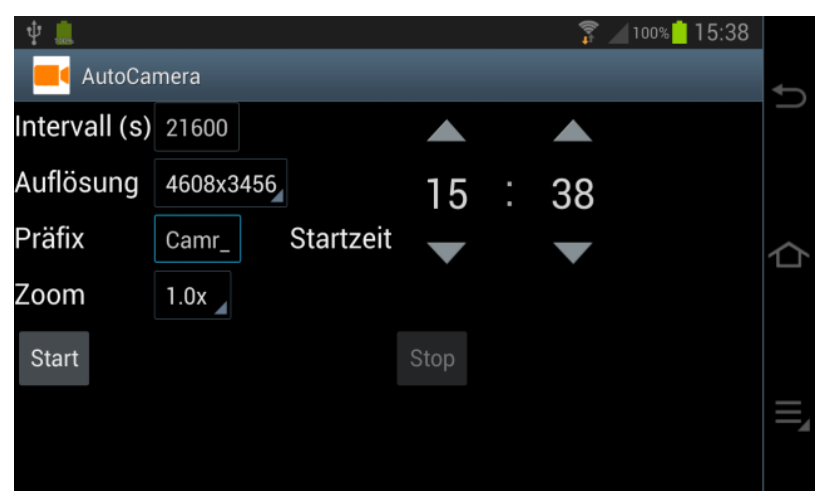

Figure 2. User interface of the image acquisition application

The two cameras were mounted on a hosting platform that allows a maximum elevation of $10 \mathrm{~m}$ at a distance of ca. $3.5 \mathrm{~m}$ to each other. That distance between the cameras was chosen in order to maintain a 1:6 base-to-distance ratio when compared to the centre of the observed field, as suggested by Chandler et al. (2005). Figure 3 shows the hoisting platform with the mounted cameras, while Figure 1 shows where in relation to the field the two cameras were positioned. To supply the two cameras with power, they were connected by a $3 \mathrm{~m}$ standard micro-USB cable to a portable power pack which kept the cameras' batteries charged. This power pack was in turn charged by a $4.5 \mathrm{~W}$ $20 \times 30 \mathrm{~cm}$ solar panel. To ensure that the installation was weather-proof, the cameras and the power pack were placed in water-proof casings.

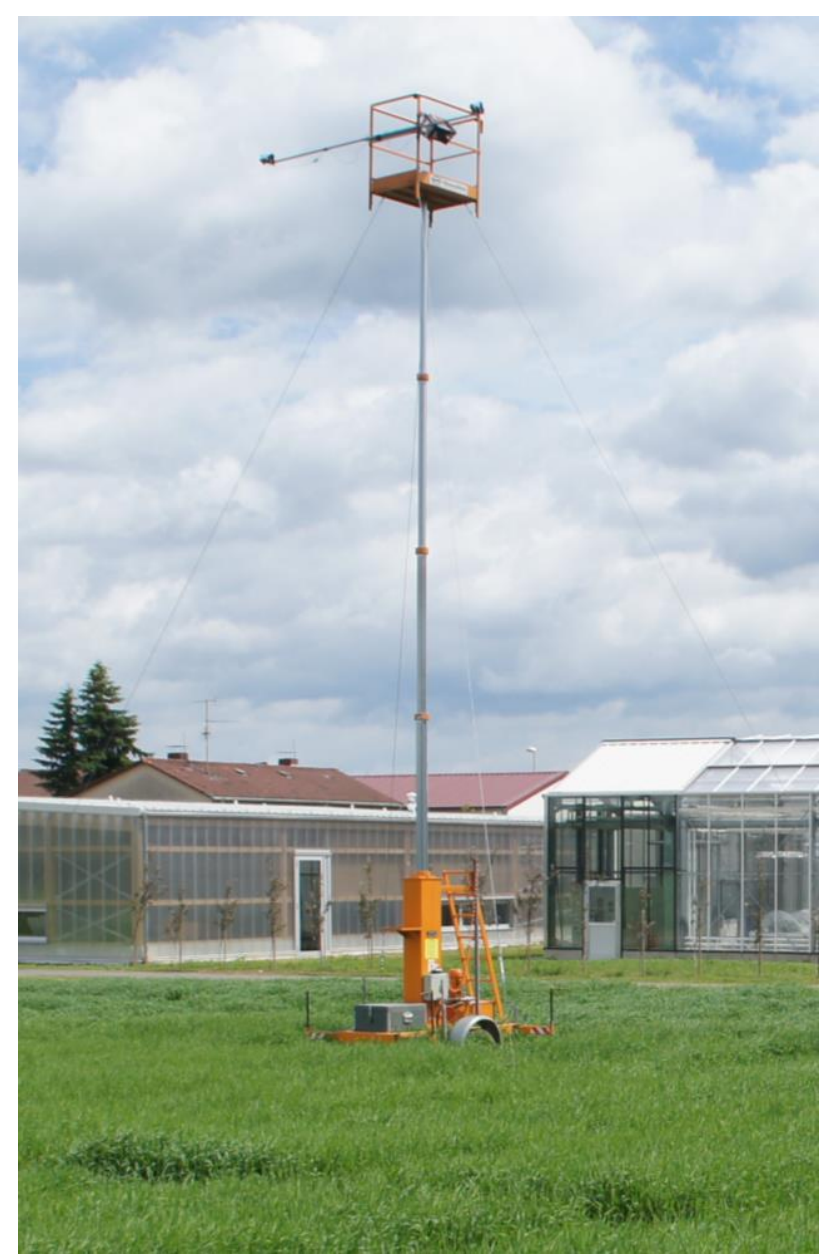

Figure 3. Hoisting platform with mounted cameras

The automated data acquisition was carried out three times daily, with an interval of six hours, from May $28^{\text {th }}$ to July $12^{\text {th }}$ 2013.

Due to technical problems with the hoisting platform and the power supply of the cameras and due to the weather, usable images for CSM generation were only acquired on or near to three of eight dates were manual height measurements were taken. The three dates were May $30^{\text {th }}$, June $13^{\text {th }}$ and June $25^{\text {th. }}$

2.2.2 Manual height measurements: During the time of automated image acquisition, additional manual measurements of plant height for verification purposes were undertaken. During the manual measuring, plant height was measured by placing a ruler next to the plants at ten representative spots per plot to then be able to calculate a mean plant height per plot with a precision of $0.01 \mathrm{~m}$. The manual measurement dates were scheduled approximately bi-weekly, thus almost covering the complete growing period of summer barley. In total, manual plant height measurements were taken eiht times during the growing period: On April $29^{\text {th }}$, May $14^{\text {th }}$, May $28^{\text {th }}$, June $5^{\text {th }}$, June $12^{\text {th }}$, June $25^{\text {th }}$, July $9^{\text {th }}$ and July $22^{\text {nd }}$. 
2.2.3 Ground control measurements: For ground control and to georeference the generated $3 \mathrm{~d}$ crop surface models, the corners of all plots in the field containing the eight observed plots were measured using the highly accurate Topcon HiPer Pro DGPS system (Topcon Positioning Systems Inc., 2006). From the GPS derived elevation of these ground control points, a base elevation raster was created by first creating a TIN and then interpolating a ground raster using a nearest neighbour interpolation.

\subsection{Data processing}

Data processing was performed using the software package Agisoft PhotoScan Professional in the version 1.0.4 build 1847. This software package uses Structure from Motion algorithms to reconstruct the three-dimensional screen geometry, the camera positions and the internal camera calibration parameters by detecting image features such as object edges and tracking their different positions in multiple images; subsequently, dense multiview stereo reconstruction algorithms are used to build the majority of geometric scene details (Verhoeven, 2011). The GIS software package Esri ArcGIS 10.2.1 was used for the generation of the raster-based crop surface models. In a first step, all image pairs taken within one day of the manual plant height measurements were selected. For each measurement date, the best image pair was selected. This selection was based on a manual visual inspection; images that e.g. had a very low contrast or that were taken during rainfall and thus had raindrops visible on the camera casing were discarded. See Figure 4 for examples of usable and unusable image acquisitions.

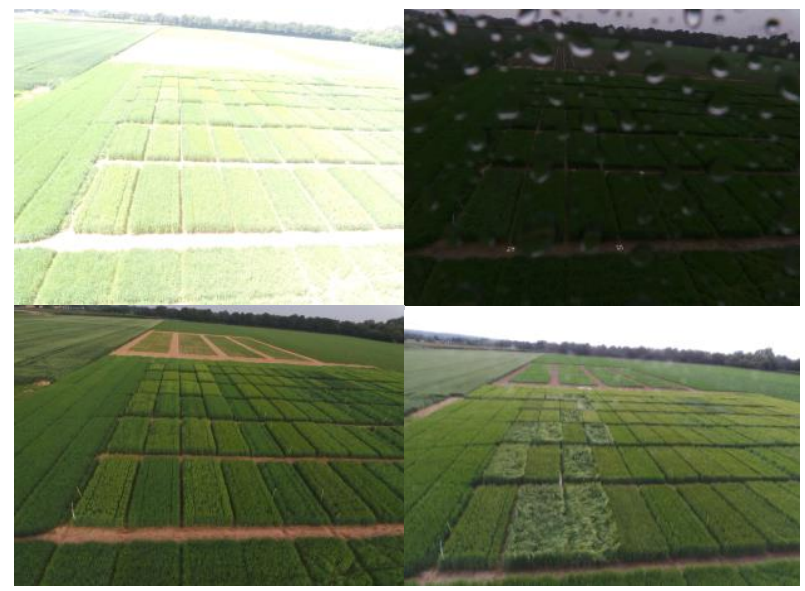

Figure 4. samples of unusable (top) and usable images (bottom)

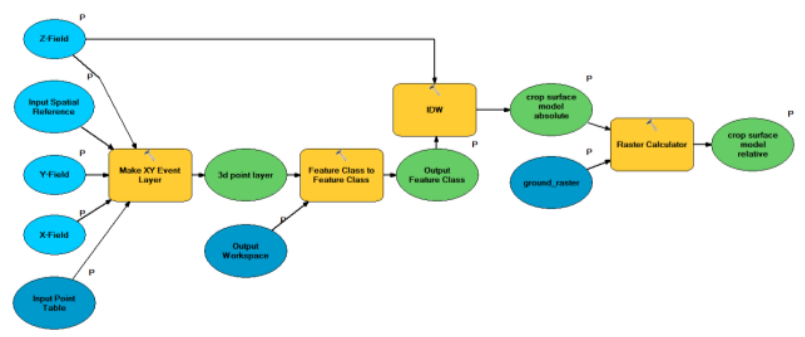

Figure 5: ArcGIS model to create the CSM from the dense point
After appropriate image pairs were selected, all visible plot corners were marked in each image as ground control points, and their $\mathrm{X}, \mathrm{Y}$ and $\mathrm{Z}$ coordinates were set as measured by the Topcon HiperPro DGPS system. Next, the photos were aligned using the "Align Photos" function in PhotoScan. During alignment, PhotoScan estimates both internal and external camera orientation parameters, including nonlinear radial distortions (Agisoft 2014). Subsequently, the dense point cloud was generated using the "Medium Quality" setting in PhotoScan; the "High Quality" and "Very High Quality" settings resulted in dense point clouds were for large parts of the observed images, no points were generated at all. After generating the dense point clouds, they were exported to comma-separated .CSV files for further analysis in ArcGIS. For automating the workflow in ArcGIS, a model was developed using the ModelBuilder that creates an interpolated crop surface model from the input .CSV file containing the dense point cloud. The model workflow can be seen in Figure 5: A feature class is generated from the .CSV point file, and a crop surface model is then interpolated using an inverse distance weighted (IDW) technique. For the interpolation, a search radius of 12 points within a distance of $0.5 \mathrm{~m}$ was chosen. Finally, to generate a crop surface model containing the relative plant height and not the absolute surface height, the ground elevation raster created using the ground control points is subtracted from the interpolated raster. This is realized by using the "Raster Calculator" functionality. Statistics for each observed plot for each generated CSM were calculated using the "Zonal Statistics as Table" tool. For the plot outlines for the zonal statistics, a polygon of the plots created by using the GPS-measured corners of the plots was used. The plot borders were inset by $40 \mathrm{~cm}$ to eliminate border effects. Minimum, maximum and mean elevations were calculated per plot.

\section{RESULTS}

\subsection{Statistical Analysis}

Table 1 shows the mean, maximum and minimum plant height values as well as the standard deviations for the manual measurements as well as for the three generated CSMs across all eight observed plots. Negative minimum plant height values were recorded for four plots, in total five plot-measurement date combinations contained negative plant heights. Apart from the negative heights, plant height as derived from the CSMs ranged from 12 to $102.7 \mathrm{~cm}$ over all dates. The manually measured heights ranged from 12 to $106 \mathrm{~cm}$ across all dates. Mean as well as minimum and maximum height all increased from date to date as expected due to plant development in all but one cases for the manually measured plant heights. The one exception can be explained due to lodging of the plants in the respective plot at the respective time. Between the May $30^{\text {th }}$ and June $13^{\text {th }}$, the mean plant height increased with plant development in seven out of eight plots for the CSM-derived plant heights. The standard deviation was lower for the manually measured control heights for all but one of the plot-measurement date combinations. Figure 7 shows the correlation of plant heights derived from the generated CSMs to the manually measured plant heights. Overall, the manually measured mean plant heights correlate to the CSM-generated mean plant heights with a correlation coefficient of 0.79 , the coefficient of determination $\mathrm{R}^{2}$ is 0.62 . When looking at the three dates separately, correlation is much lower, especially for the earliest date, due to two plots from the right hand sides of the source images showing negative plant height: The correlation coefficient is 0.59 for the data from May $30^{\text {th }}$, with an $\mathrm{R}^{2}$ of 0.35 . For 
especially the second and less so the third dates, the correlation is comparable to that of the overall dataset, as is the coefficient of determination: The data from June $12^{\text {th }} / \mathrm{June} 13^{\text {th }}$ has a correlation coefficient of 0.78 with an $\mathrm{R}^{2}$ of 0.61 . For the June $26^{\text {th }}$ measurements, the coefficient of correlation is 0.70 with an $\mathrm{R}^{2}$ of 0.49 . The lower correlation and $\mathrm{R}^{2}$ in the last date can be explained by the lodging in several plots that resulted in difficulties in finding representative plants to measure manually. Standard deviations per plot were uniform at 5.35 or lower for the manually measured heights, except for the plots were lodging occurred (plots 2, 3 and 16 on June $25^{\text {th }}$ ) and plot 15 on June $12^{\text {th }}$. Within each plot, the standard deviations for the manual plant height measurements stay relatively constant over time, except for the plots that showed lodging. This is expected as it reflects the different varieties of barley being cultivated in the different plots.

The range of the manual plant height measurements grew through time when looking at the overall data; the further the plants are developed the higher the range was. The same cannot be said of the CSM-derived plant heights. The reason for that can be found in the negative minimum plant heights found in two of the CSMs

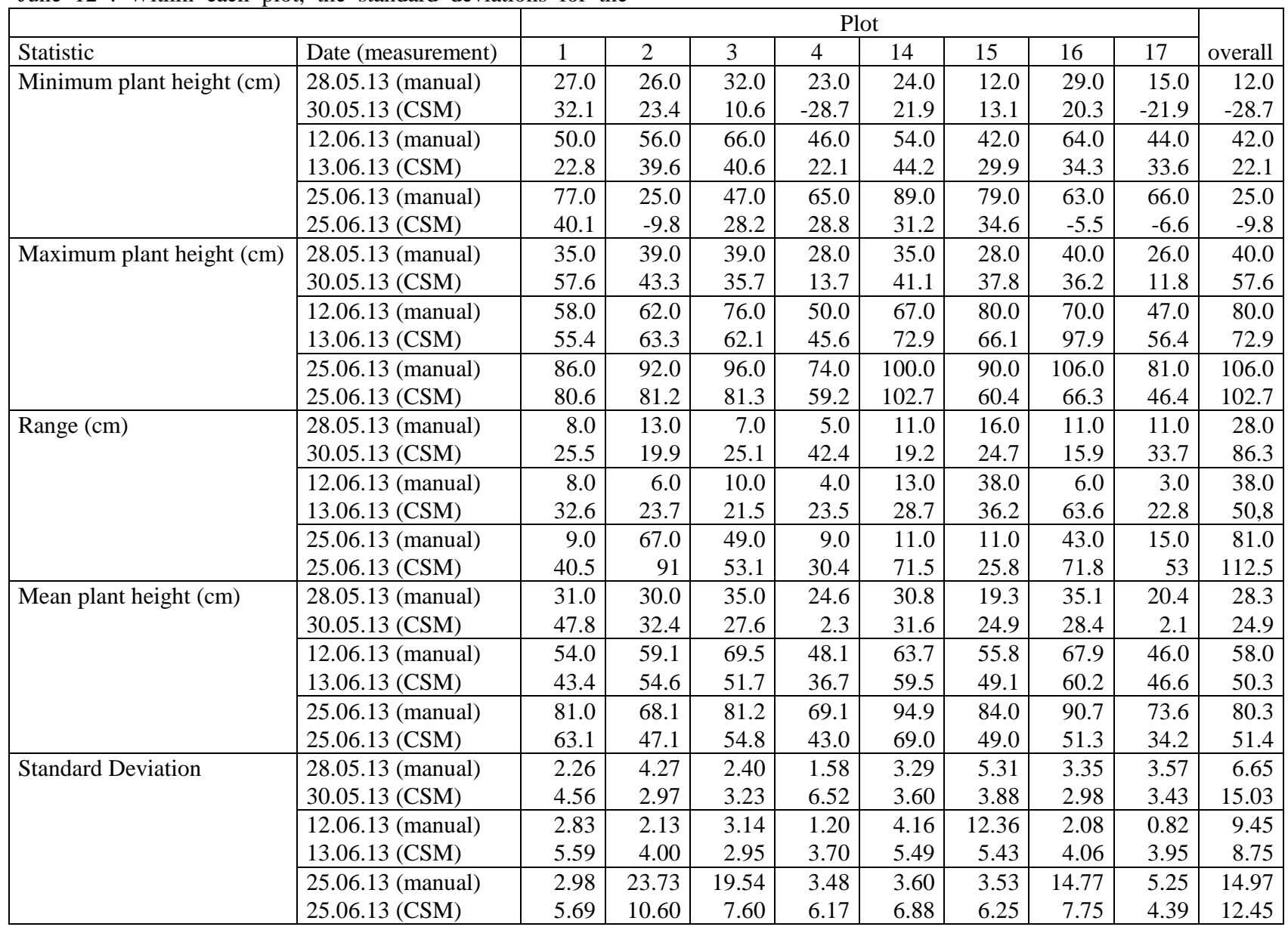

Table 1. Descriptive statistics of plant heights, measured and CSM-derived
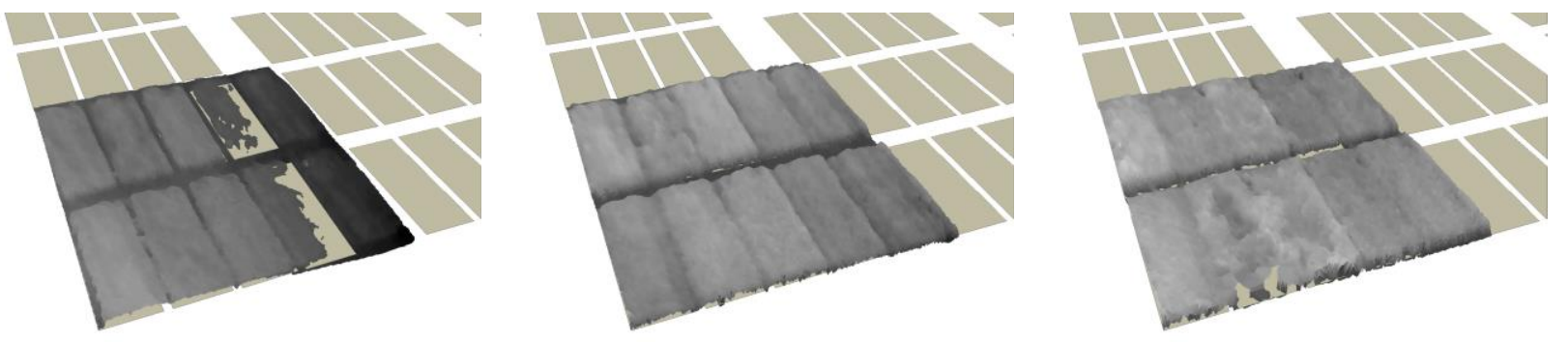

Figure 6. The three generated CSMs (unobserved plots shown for reference) left: May $30^{\text {th }}$, middle: June $13^{\text {th }}$, right: June $25^{\text {th }}$ 


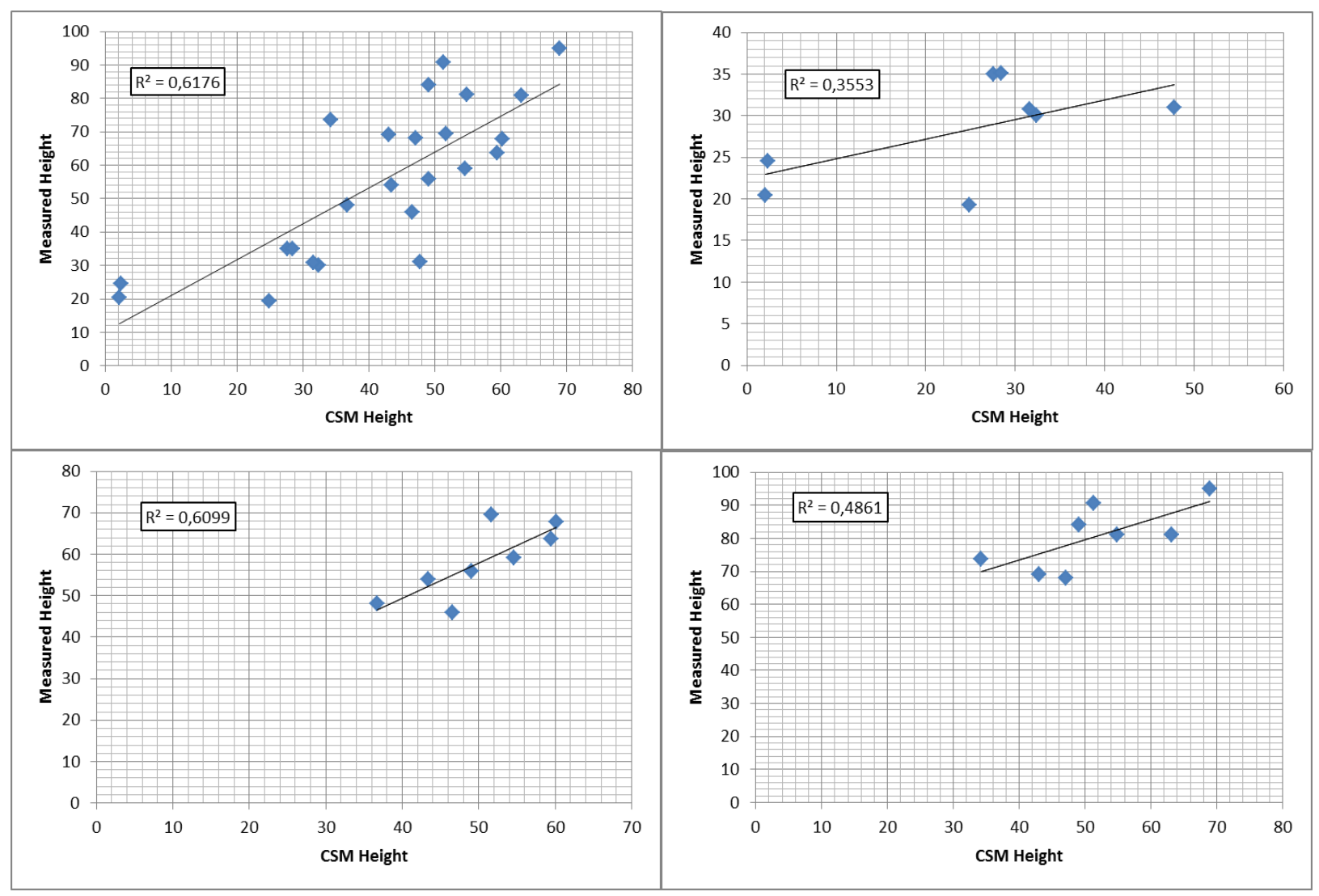

Figure 7. Correlation between CSM-derived plant heights and manually measured heights, Top left: overall, Top right: $30^{\text {th }}$ May, Bottom left: $12^{\text {th }} / 13^{\text {th }}$ June, Bottom right: $25^{\text {th }}$ June

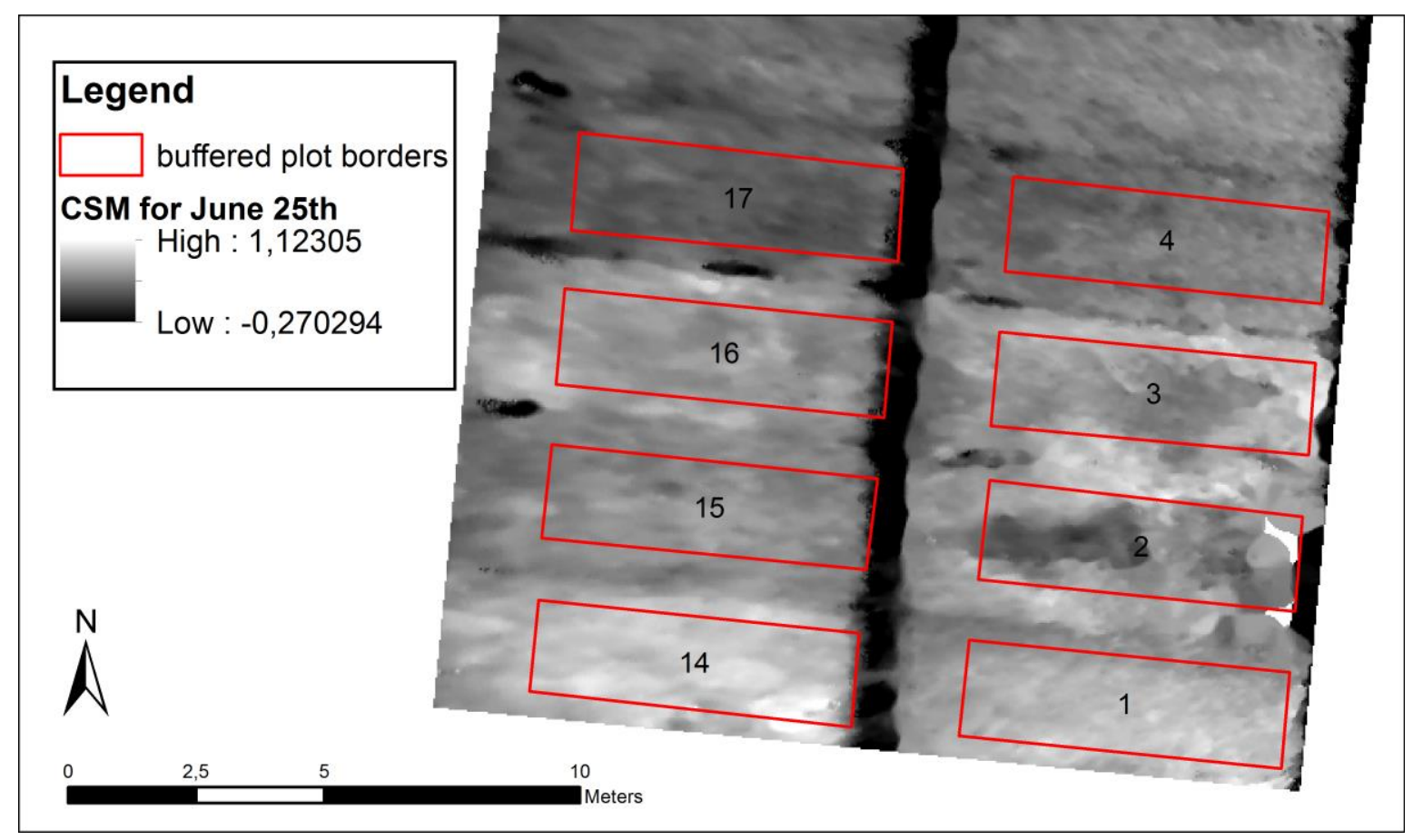

Figure 8. CSM for June $30^{\text {th }}$ and plot borders buffered by $40 \mathrm{~cm}$ 


\subsection{Crop Surface Models}

The three generated CSMs with a $0.01 \mathrm{~m}$ resolution are visualized in Figure 6. The plots can be easily distinguished. It is unclear why parts of plots 4 and 17 in the CSM from measurements taken on May $30^{\text {th }}$ show an elevation lower than the base terrain elevation established by the interpolation of the ground control points' elevation. This negative plant height result can also be seen in Table 1 in the minimum plant elevation values for the first date for plots 4 and 17. Plots 2 and 3 show distortions in the CSM for the date of June $25^{\text {th }}$; this is due to lodging that occurred in these plots due to severe rainfalls in the preceding days. Especially in the two latter CSMs, the length of the plots has been overestimated when compared to the actual plot borders as measured by the DGPS.

\section{DISCUSSION}

The cause for the overall low and negative minimum CSM plant height values in the two rightmost plots in the CSM for May $30^{\text {th }}$ is unclear. Further research is necessary to find the cause for this effect, a possible cause could be that in the images acquired on this date, circular reflections from the weatherproofing of the cameras was visible which might have adverse effects on the generation of the CSM. During later image acquisition, the weather-proofing was improved to prevent such reflections from occurring. The reason for the negative minimum heights in the CSMs for the last date in plots 2, 16 and 17 is possibly the distortion in the CSM caused by the lodging of the plants. An alternative explanation might be that border effects are appearing and that the $40 \mathrm{~cm}$ buffer applied to the measured plot borders was not enough. The buffer size was increased compared to the $30 \mathrm{~cm}$ border effect buffer applied by Bendig et al. (2013) to pre-emptively account for an increase in border effects due to the fact that here, oblique images were acquired, compared to the UAV-based nadir image acquisition used in the work of Bendig et al. (2013). Due to the overestimation of the length of the plots in the CSMs, especially at the two latter dates, the zone file for the zonal statistics assigned areas that are actually outside of the plots as belonging to the plots, resulting in the very low minimum plant height values. This can be seen in Figure 8 , the plots in the CSM stretch across the clear ground between the front and back row of plots.

This is most likely caused by the poor choice of ground control points: Especially in the latter growing stages of the plants, the corners of the plots of the back row are no longer easily identifiable due to being obscured by the plants in the front row of plots, as can be seen in the bottom right image in Figure 4.

\section{CONCLUSION}

Overall, the data quality of the generated CSMs is improvable. This is due to several factors: Technical issues with the cameras and the hoisting platform necessitated repeated mounting and unmounting of the cameras, leading to different camera positions throughout the time period covered by the image acquisition. Secondly, during the latter image acquisition dates, determining the exact location of the plot corners used as ground control points became difficult, some were covered due to the height of the crops in the plot in front of them. This lead to the underestimation of the crop height in the CSM generated for the latest date. In future experiments, it is planned to use better GCPs in locations that will be visible to the camera throughout the image acquisition campaign. Measuring both the location of the GCPs and the camera positions using a total station should also provide higher accuracy in the generated CSMs. It is also planned to use the automated in-image GCP detection in Agisoft Photoscan to further automate the CSM generation. Selecting "good" stereo image pairs for CSM generated could be automated by using image quality assessment algorithms. Further work along the lines of Wackrow et al. (2007) to further test the applicability of the smart cameras used in this paper for photogrammetric measurements would also be advantageous.

\section{REFERENCES}

Agisoft 2014. Agisoft PhotoScan User Manual: Professional Edition, Version 1.0.0, http://www.agisoft.ru/pdf/photoscan_pro_1_0_en.pdf, (24-072014)

Bendig, J., Bolten, A. and Bareth, G., 2013. UAV-based imaging for multi-temporal, very high resolution crop surface models to monitor crop growth variability. Photogrammetrie Fernerkundung - Geoinformation, 2013(6), pp. 551-562.

Chandler, J., Ashmore, P., Paola, C., 2002. Monitoring riverchannel change using terrestrial oblique digital imagery and automated digital photogrammetry. Annals of the Association of American Geographers, 92(4), pp. 631-644.

Chandler, J. H., Fryer, J. G., Jack, A., 2005. Metric capabilities of low-cost digital cameras for close range surface measurements. The Photogrammetric Record, 20(109), pp. 1226.

Habib, A., Jarvis, A., Detchev, G., Stensaas, G., Moe, D., Christopherson, J., 2008. Standards and specifications for the calibration and stability of amateur digital camaras for closerange mapping applications. The International Archives of Photogrammetry, Remote Sensing and Spatial Information Sciences-ISPRS Congress Beijing 2008 (2008), 37(B1), pp. 1059-1064

Heng, B.C.P., Chandler, J.H., 2010. Applying close range digital photogrammetry in soil erosion studies. The Photogrammetric Record, 25, pp. 240-265.

James, M., Robson, S., 2012. Straightforward reconstruction of 3D surfaces and topography with a camera: Accuracy and geoscience application. Journal of Geophysical Research, 117(F3), pp. F03017

James, M., Varley, N., 2012. Identification of structural controls in an active lava dome with high resolution DEMs: Volcán de Colima, Mexico. Geophysical Research Letters, 39(22), pp. L22303.

Hoffmeister, D., Bolten, A., Curdt, C., Waldhoff, G., Bareth, G., 2010. High-resolution Crop Surface Models (CSM) and Crop Volume Models (CVM) on field level by terrestrial laser scanning. SPIE Proceedings, 7840, pp. 78400E-78400E-6.

Mulla, D. J., 2013. Twenty-five years of remote sensing in precision agriculture: Key advanced and remaining knowledge gaps. Biosystems Engineering, 114(4), pp. 358-371

Samsung, 2014. Galaxy Camera - Wifi \& 3G specifications, http://www.samsung.com/uk/support/model/EK-

GC100ZWABTU (24-07-2014) 
Tilly, N., Hoffmeister, D., Ciao, Q., Huang, S., Miao, Y., LenzWiedemann, V. and Bareth, G., 2014. Multi-temporal crop surface models: Accurate plant height measurement and biomass estimation with terrestrial laser scanning in paddy rice. J. Applied Remote Sensing, 8(1), pp. 083671.

Topcon Positioning Systems, Inc., 2006. HiPer Pro Operator's Manual, http://www.top-survey.com/topsurvey/downloads/HiPerPro_om.pdf (04. Aug. 2014)

Verhoeven, G., 2001. Taking computer vision aloft Archaelogical three-dimensional reconstructions from aerial photographs with PhotoScan. Archaeological Prospection, 18, pp. 67-73.

Wackrow, R., Chandler, J. H., Bryan, P, 2007. Geometric consistency and stability of consumer-grade digital cameras for accurate spatial measurement. The Photogrammetric Record, 22(118), pp. 121-134. 